\title{
Risk factors and outcomes of intraoperative atrial fibrillation in patients undergoing thoracoscopic anatomic lung surgery
}

\author{
Chaoyang Tong ${ }^{1 \#}$, Qi Zhang ${ }^{1 \#}$, Yuan Liu ${ }^{2}$, Meiying Xu ${ }^{1}$, Jingxiang $\mathrm{Wu}^{1}$, Hui Cao ${ }^{1}$ \\ ${ }^{1}$ Department of Anesthesiology Shanghai Chest Hospital, Shanghai Jiao Tong University, Shanghai, China; ${ }^{2}$ Statistical Center, Shanghai Chest \\ Hospital, Shanghai Jiao Tong University, Shanghai, China \\ Contributions: (I) Conception and design: H Cao, J Wu, M Xu; (II) Administrative support: None; (III) Provision of study materials or patients: None; \\ (IV) Collection and assembly of data: C Tong, Q Zhang; (V) Data analysis and interpretation: C Tong, Y Liu, H Cao; (VI) Manuscript writing: All \\ authors; (VII) Final approval of manuscript: All authors. \\ \#These authors contributed equally to this work as co-first authors. \\ Correspondence to: Hui Cao. Department of Anesthesiology, Shanghai Chest Hospital, Shanghai Jiao Tong University, 241 Huaihai Rd. West, \\ Shanghai, China. Email: drcaohui@163.com; Jingxiang Wu. Department of Anesthesiology, Shanghai Chest Hospital, Shanghai Jiao Tong University, \\ 241 Huaihai Rd. West, Shanghai 200030, China. Email: wjx1132@163.com.
}

Background: Atrial fibrillation (AF) is common after thoracoscopic anatomic lung surgery and can be associated with increased adverse outcomes. However, the incidence, risk factors, and related outcomes of intraoperative AF in thoracoscopic anatomical lung surgery are unknown.

Methods: We retrospectively analyzed the files of 14,986 patients who had presented to the Shanghai Chest Hospital for thoracoscopic anatomic lung operations between January 2016 and December 2018. Univariate and multivariate analyses were conducted to identify risk factors for intraoperative AF, and a 1:1 propensity score-matched (PSM) analysis was performed to compare postoperative outcomes.

Results: The incidence of intraoperative AF was 1.2\% (177/14,986). Multivariate analysis identified age older than or equal to 60 years [odds ratio $(\mathrm{OR})=1.872, \mathrm{P}<0.001$ ], male sex $(\mathrm{OR}=2.979, \mathrm{P}<0.001)$, diabetes mellitus $(\mathrm{OR}=2.287, \mathrm{P}=0.014)$, lesion diameter of $1.4 \mathrm{~cm}$ or larger $(\mathrm{OR}=1.855, \mathrm{P}=0.002)$, clinical nodal involvement $(\mathrm{OR}=1.920, \mathrm{P}=0.005)$, lobectomy resection $(\mathrm{OR}=2.958, \mathrm{P}=0.001)$, and right resection $(\mathrm{OR}=1.475, \mathrm{P}=0.021)$ as independent risk factors for intraoperative AF. After 1:1 PSM, we evaluated outcomes in 350 (175 pairs) patients with or without intraoperative AF. Patients who had intraoperative AF were associated with prolonged median ICU stay $\{28$ [26-54] vs. 24 [22-44] hours, $\mathrm{P}=0.001\}$ and length of stay (LOS) $\{6$ [4-7] vs. 5 [4-6] days, $\mathrm{P}=0.009\}$. However, the differences in cardiovascular, pulmonary, and other complications were not significant. In the subgroup analysis, patients who recovered sinus rhythm during operation $(\mathrm{n}=16)$ had a shorter median $\operatorname{LOS}\{4$ [4-6] vs. 6 [4-7] days, $\mathrm{P}=0.031\}$, and a similar incidence of complications compared with patients who recovered sinus rhythm after surgery $(\mathrm{n}=159)$.

Conclusions: We identified 7 independent risk factors for intraoperative AF, which were associated with prolonged ICU and hospital stays. The findings may help clinicians identify high-risk patients and take preventive measures to minimize the incidence and adverse outcomes of intraoperative AF.

Keywords: Thoracic surgery; intraoperative atrial fibrillation; risk factors; video-assisted thoracoscopic surgery (VATS)

Submitted Jun 30, 2020. Accepted for publication Dec 10, 2020.

doi: $10.21037 /$ atm-20-5035

View this article at: http://dx.doi.org/10.21037/atm-20-5035 


\section{Introduction}

Video-assisted thoracoscopic surgery (VATS) is a minimally invasive method which has been increasingly used for anatomical lung resection. VATS greatly reduces surgical stress, systemic inflammation and postoperative complications (1-3), and when accompanied by systematic lymph node dissection, is the best curative treatment for lung cancer. Postoperative atrial fibrillation (POAF) is a common surgical complication in thoracoscopic anatomic lung resection, with a reported incidence ranging from $12 \%$ to $32 \%(4-7)$ and is associated with increased short- and long-term adverse outcomes (6-11).

Several attempts at identifying risk factors for POAF have been made, and these studies have shown that advanced age, male sex, higher body mass index, race, higher preoperative rest heart rate, extent of surgical resection, history of congestive heart failure, history of arrhythmias, and brain natriuretic peptide are known as independent risk factors for POAF $(4,6-9,12)$. The mechanism of POAF is mainly related to decreased cardiopulmonary reserve, systemic inflammatory response to surgery, enhanced sympathetic nervous system activity, postoperative high stress state, and peroxidative stress response $(13,14)$, but whether the mechanism of intraoperative $\mathrm{AF}$ is consistent with $\mathrm{POAF}$ is still unclear. Although guidelines exist concerning the treatment of POAF (9), there is a lack of clinical experience in the management of intraoperative AF, especially when it causes significant hemodynamic fluctuations. Therefore, to provide evidence for the clinical practice of preventing intraoperative $\mathrm{AF}$ and related adverse outcomes in high-risk patients, we conducted this large sample study to explore the potential risk factors.

We present the following article in accordance with the STROBE reporting checklist (available at http://dx.doi. org/10.21037/atm-20-5035).

\section{Methods}

We conducted a single-center retrospective study of 15,419 patients who had undergone thoracoscopic anatomic lung surgery between January 2016 and December 2018. Patients who met any of the following criteria were excluded from the study: preoperative AF $(\mathrm{n}=90)$, non-sinus rhythm $(n=22)$, conversion to thoracotomy from VATS $(n=195)$, thoracoscopic sleeve lobectomy $(\mathrm{n}=67)$, pneumonectomy $(n=39)$, or bilateral lung resection $(n=20)$. The study was conducted in accordance with the Declaration of Helsinki (as revised in 2013) and was approved by the Institutional Review Board at Shanghai Chest Hospital (No. KS1230). Informed consent was waived because of the retrospective nature of the study.

\section{Data collection, outcomes, and definitions}

Perioperative medical data were extracted from the electronic recording system of our institution, including patient demographics, medical history, surgical procedures, cancer clinical stage, and outcomes. Outcomes included postoperative pulmonary complications (PPCs), cardiovascular complications and other related surgical complications, intensive care unit (ICU) stay, and the length of hospital stay (LOS). PPCs are defined according to the European Perioperative Clinical Outcome (EPCO) (15). The definition for intraoperative AF was based on 2014 American Association for Thoracic Surgery (AATS) guidelines (9), and included the onset of intraoperative $\mathrm{AF}$ recorded from the electrocardiogram (ECG) lasting at least 1 minute.

\section{Technique of operation}

The number of lung operations in the Shanghai Chest Hospital has approached 10,000 cases each year since 2016, of which VATS accounts for more than $80 \%$. Our center has 13 surgical teams, each including a chief surgeon and 1-2 surgical assistants. Considering the surgeons perform an average of 384 cases per year, we divided the teams into two groups ( $<400 /$ year $v s . ~ \geq 400 /$ year). In all patients, surgical resection with systematic lymph node dissection was considered as the best curative treatment for lung cancer.

\section{Statistical analysis}

Statistical analysis was performed using SPSS 25.0 software (SPSS Inc., IBM Corp., Armonk, NY, USA). Two-sample independent $t$-test or Wilcoxon rank-sum test were used to compare the potential differences of continuous variables, while chi-square or Fisher's exact test for small samples were used to compare the categorical variables. Kaplan-Meier estimates were used for ICU stay and LOS. All variables found to be significantly $(\mathrm{P}<0.1)$ associated with intraoperative $\mathrm{AF}$ by univariate analysis were selected for the multivariable logistic regression model. Discrimination (C index) and calibration (Hosmer-Lemeshow goodness-of-fit test) were adopted to assess the prediction model. To determine the thresholds for age and lesion diameter, receiving operator 


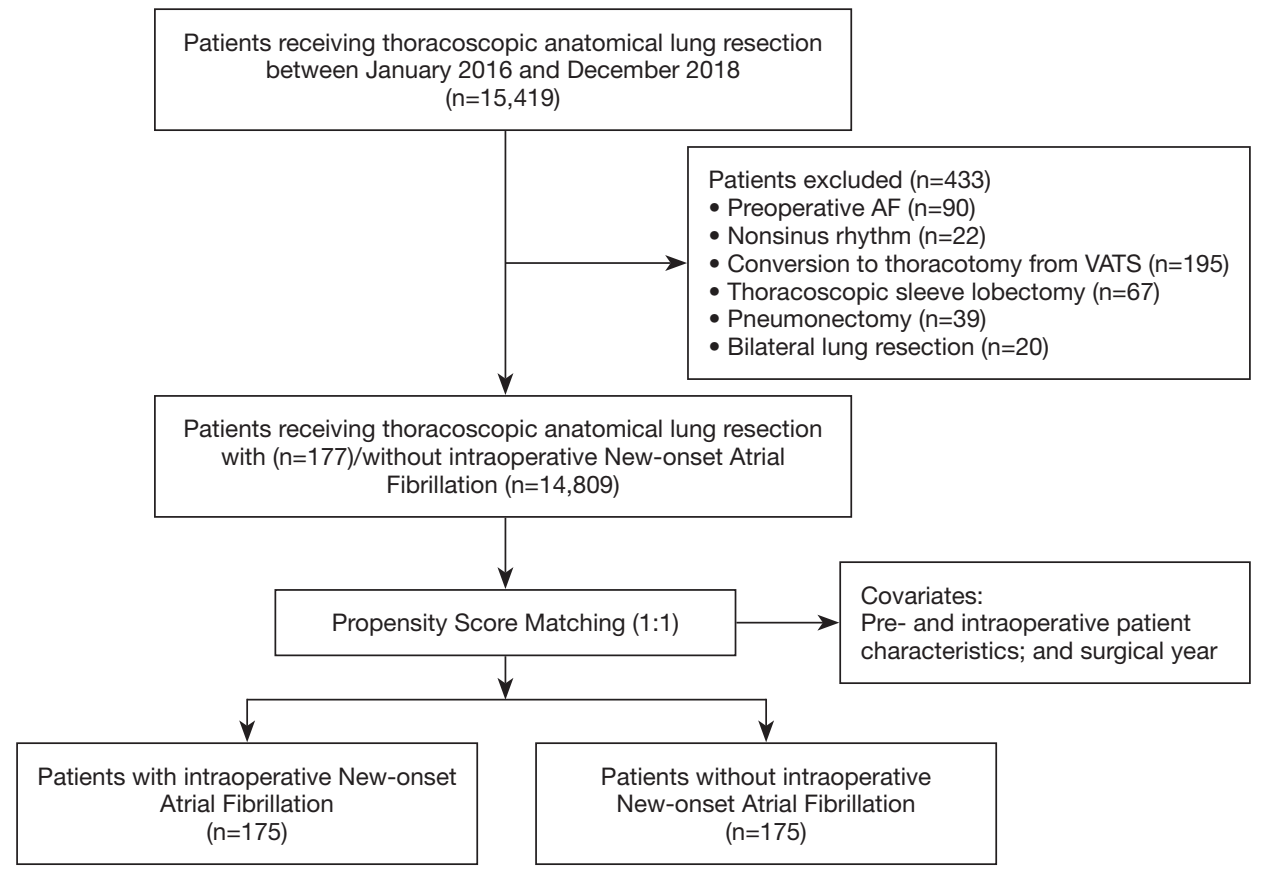

Figure 1 Patient flowchart.

characteristic (ROC) analysis was performed. A P value $<0.05$ was considered statistically significant.

\section{Matching}

Based on pre- and intraoperative variables and surgical years, a 1:1 propensity score matching (PSM) (16) with a caliper size of 0.001 was conducted to reduce the effects of confounding factors and compare outcomes between intraoperative $\mathrm{AF}$ and non-AF. After 1:1 PSM, all patient characteristics and surgical years were found to be comparable among the two groups. A subgroup analysis comparing patients with intraoperative AF who recovered sinus rhythm during the operation or after surgery was also carried out. All patients who failed to achieve sinus rhythm during the surgery eventually recovered sinus rhythm in the postoperative period.

\section{Results}

Between January 2016 and December 2018, 14,986 patients received thoracoscopic anatomical lung resection, with $22.0 \%(3,301$ of 14,986$)$ receiving segmentectomy resection and $78.0 \%(11,685$ of 14,986$)$ receiving lobectomy resection. Of these, $1.2 \%$ of patients (177 of 14,986) experienced AF during the operation (Figure 1).
The incidence of intraoperative AF dropped from 81 of $4,340(1.9 \%)$, to 51 of 5,069 (1.0\%), to 45 of $5,577(0.8 \%)$ $(\mathrm{P}<0.001)$ over 3 -year intervals.

\section{Risk factors for intraoperative $A F$}

The univariate analysis found 10 significant variables related to intraoperative AF (Table 1). Multivariate analysis identified age older than or equal to 60 years [odds ratio $(\mathrm{OR})=1.872, \mathrm{P}<0.001]$, male sex $(\mathrm{OR}=2.979, \mathrm{P}<0.001)$, diabetes mellitus $(\mathrm{OR}=2.287, \mathrm{P}=0.014)$, lesion diameter of $1.4 \mathrm{~cm}$ or larger $(\mathrm{OR}=1.855, \mathrm{P}=0.002)$, clinical nodal involvement $(\mathrm{OR}=1.920, \mathrm{P}=0.005)$, lobectomy resection (vs. segmentectomy resection, $\mathrm{OR}=2.958, \mathrm{P}=0.001$ ), and right resection ( $v s$. left resection, $\mathrm{OR}=1.475, \mathrm{P}=0.021$ ) as independent risk factors for intraoperative $\mathrm{AF}$ (Table 2). The multivariable logistic regression model had good calibration (Hosmer-Lemeshow test, $\mathrm{P}=0.875$ ) and discrimination (C statistic, 0.756). The ROC analysis showed similar area under the curve threshold values of $0.644(\mathrm{P}<0.05)$ for age and lesion diameter.

\section{Outcomes after PSM (1:1)}

After 1:1 PSM, all patient characteristics and surgical 
Table 1 Pre- and intraoperative patient characteristics

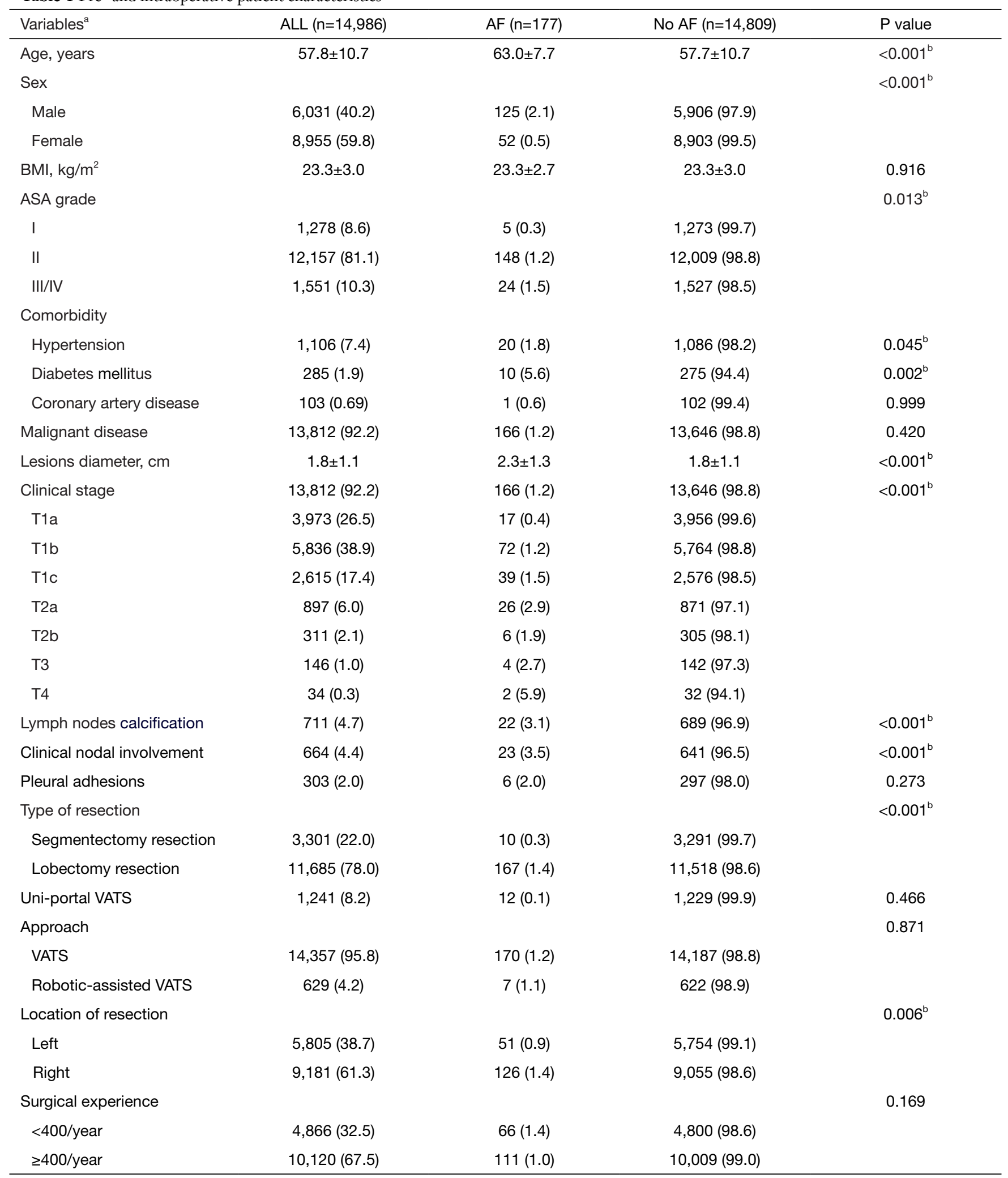

${ }^{\mathrm{a}}$, continuous data are shown as mean \pm standard deviation and categoric data as number (\%). ${ }^{\mathrm{b}}$, statistically significant $(\mathrm{P}<0.05) . \mathrm{AF}$, atrial fibrillation; ASA, American Society of Anesthesiology; BMI, body mass index; VATS, video-assisted thoracoscopic surgery. 
Table $2{ }^{a}$ Multivariable logistic regression analysis of risk factors for AF

\begin{tabular}{|c|c|c|}
\hline Variables & OR $(95 \% \mathrm{Cl})$ & $P$ value \\
\hline Male sex & $2.979(2.144-4.140)$ & $<0.001^{\mathrm{b}}$ \\
\hline Diabetes mellitus & $2.287(1.185-4.414)$ & $0.014^{b}$ \\
\hline Lesions diameter $\geq 1.4 \mathrm{~cm}$ & $1.855(1.261-2.729)$ & $0.002^{b}$ \\
\hline \multicolumn{3}{|l|}{ Type of resection } \\
\hline \multicolumn{3}{|c|}{ Segmentectomy (reference) } \\
\hline Lobectomy & $2.958(1.538-5.686)$ & $0.001^{\mathrm{b}}$ \\
\hline \multicolumn{3}{|l|}{ Location of resection } \\
\hline
\end{tabular}

${ }^{a}$, Hosmer-Lemeshow test $\mathrm{P}=0.875$; $\mathrm{C}$ statistic: 0.756 ; $\mathrm{Cl}$, confidence interval; OR, odds ratio. ${ }^{\mathrm{b}}$, statistically significant $(\mathrm{P}<0.05)$. $\mathrm{AF}$, atrial fibrillation.

years were comparable among the two groups (Table 3). We evaluated outcomes in 350 (175 pairs) patients with or without intraoperative AF. Patients who had intraoperative AF were associated with prolonged median ICU stay $\{28$ [26-54] vs. 24 [22-44] hours, $\mathrm{P}=0.001\}$ and LOS $\{6$ [4-7] vs. 5 [4-6] days, $\mathrm{P}=0.009\}$. However, the differences in cardiovascular, pulmonary, and other complications were not significant (Table 4).

\section{AF recovery during or after operation}

Among the 175 patients with intraoperative AF, 16 recovered sinus rhythm during operation, including 8 patients who recovered automatically without intervention, 5 who recovered after cardioversion, and 3 who recovered after amiodarone intervention, which took $6.9 \pm 5.8,4.0 \pm 1.0$, and 37.7 $\pm 27.6(\mathrm{P}=0.003)$ minutes, respectively (Table $\mathrm{S} 1)$. In the subgroup analysis, patients who recovered sinus rhythm during operation $(\mathrm{n}=16)$ had a shorter duration of intraoperative $\mathrm{AF}(14.6 \pm 16.4$ vs. $44.5 \pm 25.2, \mathrm{P}<0.001)$ and median LOS $\{4$ [4-6] vs. 6 [4-7] days, $\mathrm{P}=0.031\}$, but a similar incidence of complications compared with patients who recovered sinus rhythm after surgery $(\mathrm{n}=159)$ (Table $\mathrm{S} 2)$.

\section{Discussion}

The overall incidence of intraoperative AF was 1.2\%. Our study found 7 independent risk factors for intraoperative
AF which were associated with longer ICU and hospital stays. For patients with intraoperative AF, recovering sinus rhythm during operation may shorten hospital stay. The findings may help clinicians identify high-risk patients and take preventive measures to minimize the incidence and adverse outcomes of intraoperative AF.

Intraoperative $\mathrm{AF}$ has always been a concern for the surgical teams at our thoracic center. With the accumulation of unit experience, increase of cases, enhancement of confidence, and the identification of potential risk factors, intraoperative AF rates have decreased from $3.4 \%$ as previously reported (17) to $1.2 \%$ as found in our study. The incidence of intraoperative AF also dropped from 81 out of $4,340(1.9 \%)$, to 51 out of $5,069(1.0 \%)$, to 45 out of 5,577 $(0.8 \%)$ over 3 -year intervals.

Previous studies have suggested some risk factors for POAF, including advanced age, male sex, higher body mass index, race, higher preoperative rest heart rate, extent of surgical resection, history of congestive heart failure, history of arrhythmias, and brain natriuretic peptide $(4,6-9,12)$. By comparison, our study also found that advanced age, male sex, and the extent of surgical resection were still independent risk factors for intraoperative AF. Elderly patients have decreased lung function reserves, increased comorbidities, and tissue vulnerability $(13,18)$, accompanied by age-related myocardial apoptosis and fibrosis, which may contribute to the cardiac re-modelling, intra-atrial conduction delay, and re-entrant circuits 
Table 3 Pre- and intraoperative patient characteristics after PSM (1:1)

\begin{tabular}{|c|c|c|c|}
\hline Variables $^{a}$ & AF $(n=175)$ & No AF $(n=175)$ & $P$ value \\
\hline Sex & & & 0.906 \\
\hline Female sex & $51(29.1)$ & $50(28.6)$ & \\
\hline $\mathrm{BMI}, \mathrm{kg} / \mathrm{m}^{2}$ & $23.3 \pm 2.7$ & $23.5 \pm 2.8$ & 0.339 \\
\hline I & $5(2.9)$ & $4(2.3)$ & \\
\hline II & $148(84.6)$ & $144(82.3)$ & \\
\hline III/IV & $22(12.6)$ & $27(15.4)$ & \\
\hline \multicolumn{4}{|l|}{ Comorbidity } \\
\hline Malignant disease & $164(93.7)$ & $168(96.0)$ & 0.333 \\
\hline Lesions diameter, cm & $2.3 \pm 1.3$ & $2.2 \pm 1.3$ & 0.645 \\
\hline Clinical stage & $164(93.7)$ & $168(96.0)$ & 0.692 \\
\hline $\mathrm{T} 1 \mathrm{a}$ & $17(10.4)$ & $24(14.3)$ & \\
\hline $\mathrm{T} 1 \mathrm{~b}$ & $71(43.3)$ & $74(44.0)$ & \\
\hline $\mathrm{T} 1 \mathrm{c}$ & $39(23.8)$ & $33(19.6)$ & \\
\hline $\mathrm{T} 2 \mathrm{a}$ & $25(15.2)$ & $20(11.9)$ & \\
\hline $\mathrm{T} 2 \mathrm{~b}$ & $6(3.7)$ & $9(5.4)$ & \\
\hline Type of resection & & & 0.398 \\
\hline Segmentectomy resection & $10(5.7)$ & $14(8.0)$ & \\
\hline Lobectomy resection & $165(94.3)$ & $161(92.0)$ & \\
\hline Uni-portal VATS & $12(6.9)$ & $8(4.6)$ & 0.357 \\
\hline Approach & & & 0.792 \\
\hline VATS & $168(96.0)$ & $167(95.4)$ & \\
\hline Robotic-assisted VATS & $7(4.0)$ & $8(4.6)$ & \\
\hline Location of resection & & & 0.472 \\
\hline Left & $51(29.1)$ & $45(25.7)$ & \\
\hline Right & $124(70.9)$ & $130(74.3)$ & \\
\hline Surgical experience & & & 0.262 \\
\hline$<400 /$ year & $66(37.7)$ & $56(32.0)$ & \\
\hline$\geq 400 /$ year & 109 (62.3) & $119(68.0)$ & \\
\hline
\end{tabular}

${ }^{\mathrm{a}}$, continuous data are shown as mean \pm standard deviation and categoric data as number (\%). PSM, propensity score matching; AF, atrial fibrillation; ASA, American Society of Anesthesiology; BMI, body mass index; VATS, video-assisted thoracoscopic surgery. 
Table 4 Outcomes after propensity score matching (1:1)

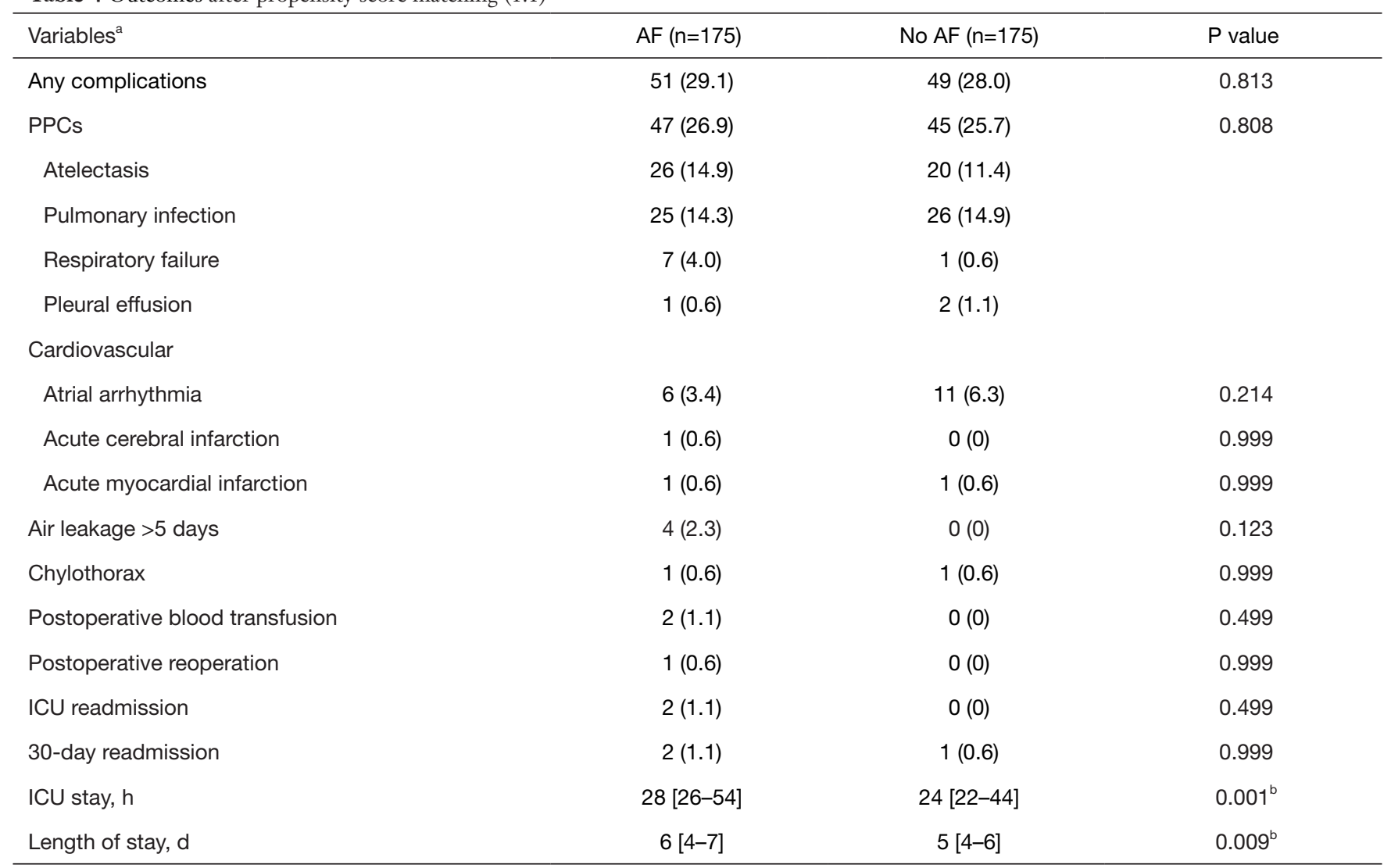

${ }^{a}$, continuous data are shown as mean \pm standard deviation and categoric data as number $(\%) ;{ }^{b}$, statistically significant $(P<0.05)$. Length of stay and ICU stay, values as median (interquartile range). AF, atrial fibrillation; PPCs, postoperative pulmonary complications; ICU, intensive care unit.

responsible for $\mathrm{AF}$. Furthermore, males have a higher risk of intraoperative AF. While the reasons for this are not fully understood, this may be due to their increased atrial size, higher pro-inflammatory immune response (19), and weaker congenital cardio-protection following surgical trauma compared to females (20-22). In addition, in accordance with other studies $(4,6,7,9,17)$, we found that compared thoracoscopic segmentectomy resection, lobectomy resection was associated with higher rates of intraoperative $\mathrm{AF}$, perhaps because of the increased lymph node removal, amount of adjacent tissues resection, higher risk of injury to the vagus nerve and its branches, and more operative time required $(23,24)$.

Our research also identified other rarely reported underlying risk factors for intraoperation $\mathrm{AF}$, including diabetes mellitus, lesion diameter $\geq 1.4 \mathrm{~cm}$, clinical nodal involvement, and right resection. Although diabetes mellitus has been rarely reported as an independent risk factor for POAF in thoracic surgery, Kalus et al. has demonstrated that patients with diabetes mellitus have a higher incidence of POAF during cardiac surgery (25), which is consistent with our study. The possible mechanism for atrial fibrillation (AF) in diabetic patients could be related to autonomic neuropathy which weakens parasympathetic activity and leads to relative sympathetic excess (24). Larger lesions (6,26) and clinical lymph node involvement (27) affected by inflammation and tumor invasion may directly mask regional anatomic areas near the vagus nerve and its branches, and increase surgical difficulty during endoscopic dissection $(28,29)$. Interestingly, we found anatomic right lung resection to be more associated with higher intraoperative AF than left lung resection, which is in line with the observations of Roselli (30). This may be related to the distribution of the vagus nerve and its branches, especially the cardiac plexus and the area near the pulmonary veins during lymph node removal $(14,23)$. 
In our study, patients who had intraoperative AF were associated with prolonged median ICU and hospital stays, while cardiovascular, pulmonary, and other complications were not significantly different compared with patients who did not suffer from intraoperative AF. These results are consistent with other studies that reported POAF to be associated with increased ICU and hospital stays $(6,7,9)$. In the subgroup analysis in this study, patients who recovered sinus rhythm during operation had a shorter duration of intraoperative $\mathrm{AF}$, a shorter median hospital stay, and a similar incidence of complications compared with patients who recovered sinus rhythm after surgery. Among the 16 patients who recovered sinus rhythm during operation, cardioversion seemed to be an effective intervention based on the time required to restore sinus rhythm. For clinicians, who encounter AF during thoracoscopic anatomic lung resection, intraoperative intervention, especially through cardioversion, may be an effective measure to shorten hospital stay.

This study has several limitations. First, as a retrospective study, it has inherent design biases. Second, although the median ICU and hospital stay in patients with intraoperative $\mathrm{AF}$ were longer compared with those in patients without intraoperative $\mathrm{AF}$, the two groups had similar short-term complications. On this basis more attention should be paid to perioperative care and the long-term prognosis of patients with intraoperative AF.

\section{Conclusions}

By conducting a retrospective analysis of 14,986 patients undergoing thoracoscopic anatomic lung operations, we identified 7 independent risk factors for intraoperative AF, which were associated with longer ICU and hospital stays. In addition, intraoperative recovery sinus rhythm may shorten hospital stay. Knowledge of these factors could help clinicians identify patients at high risk and take preventive measures to minimize the rate and adverse outcomes of intraoperative AF.

\section{Acknowledgments}

The authors would like to thank the nurses and anesthetists, along with the surgeons, Chunyu Ji and Bin Li, at Shanghai Chest Hospital for their involvement and support.

Funding: This work was supported by the National Natural Science Foundation of China (No. 82071233) and the Shanghai Municipal Commission of Health and Family
Planning Project (No. 201840319).

\section{Footnote}

Reporting Checklist: The authors have completed the STROBE reporting checklist. Available at http://dx.doi. org/10.21037/atm-20-5035

Data Sharing Statement: Available at http://dx.doi. org/10.21037/atm-20-5035

Conflicts of Interest: All authors have completed the ICMJE uniform disclosure form (available at http://dx.doi. org/10.21037/atm-20-5035). The authors have no conflicts of interest to declare.

Ethical Statement: The authors are accountable for all aspects of the work in ensuring that questions related to the accuracy or integrity of any part of the work are appropriately investigated and resolved. The study was conducted in accordance with the Declaration of Helsinki (as revised in 2013) and was approved by the Institutional Review Board at Shanghai Chest Hospital (KS1230). Informed consent was waived because of the retrospective nature of the study.

Open Access Statement: This is an Open Access article distributed in accordance with the Creative Commons Attribution-NonCommercial-NoDerivs 4.0 International License (CC BY-NC-ND 4.0), which permits the noncommercial replication and distribution of the article with the strict proviso that no changes or edits are made and the original work is properly cited (including links to both the formal publication through the relevant DOI and the license). See: https://creativecommons.org/licenses/by-nc-nd/4.0/.

\section{References}

1. Whitson BA, Groth SS, Duval SJ, et al. Surgery for earlystage non-small cell lung cancer: a systematic review of the video-assisted thoracoscopic surgery versus thoracotomy approaches to lobectomy. Ann Thorac Surg 2008:86:2008-16.

2. Paul S, Altorki NK, Sheng S, et al. Thoracoscopic lobectomy is associated with lower morbidity than open lobectomy: a propensity-matched analysis from the STS database. J Thorac Cardiovasc Surg 2010:139:366-78.

3. Falcoz PE, Puyraveau M, Thomas PA, et al. Video- 
assisted thoracoscopic surgery versus open lobectomy for primary non-small-cell lung cancer: a propensitymatched analysis of outcome from the European Society of Thoracic Surgeon database. Eur J Cardiothorac Surg 2016:49:602-9.

4. Vaporciyan AA, Correa AM, Rice DC, et al. Risk factors associated with atrial fibrillation after noncardiac thoracic surgery: analysis of 2588 patients. J Thorac Cardiovasc Surg 2004;127:779-86.

5. Roselli EE, Murthy SC, Rice TW, et al. Atrial fibrillation complicating lung cancer resection. J Thorac Cardiovasc Surg 2005;130:438-44.

6. Onaitis M, D'Amico T, Zhao Y, et al. Risk factors for atrial fibrillation after lung cancer surgery: analysis of the society of thoracic surgeons general thoracic surgery database. Ann Thorac Surg 2010;90:368-74.

7. Bhave PD, Goldman LE, Vittinghoff E, et al. Incidence, predictors, and outcomes associated with postoperative atrial fibrillation after major noncardiac surgery. Am Heart J 2012;164:918-24.

8. Alonso-Coello P, Cook D, Xu SC, et al. Predictors, Prognosis, and Management of New Clinically Important Atrial Fibrillation After Noncardiac Surgery: A Prospective Cohort Study. Anesth Analg 2017;125:162-9.

9. Frendl G, Sodickson AC, Chung MK, et al. 2014 AATS guidelines for the prevention and management of perioperative atrial fibrillation and flutter for thoracic surgical procedures. Executive summary. J Thorac Cardiovasc Surg 2014;148:772-91.

10. Imperatori A, Mariscalco G, Riganti G, et al. Atrial fibrillation after pulmonary lobectomy for lung cancer affects long-term survival in a prospective single-center study. J Cardiothorac Surg 2012:7:4.

11. Gialdini G, Nearing K, Bhave PD, et al. Perioperative atrial fibrillation and the long-term risk of ischemic stroke. JAMA 2014;312:616-22.

12. Amar D, Zhang H, Tan KS, et al. A brain natriuretic peptide-based prediction model for atrial fibrillation after thoracic surgery: Development and internal validation. J Thorac Cardiovasc Surg 2019;157:2493-9.e1.

13. Amar D. Perioperative atrial tachyarrhythmias. Anesthesiology 2002;97:1618-23.

14. Haverkamp W, Hachenberg T. Post-thoracotomy dysrhythmia. Curr Opin Anaesthesiol 2016;29:26-33.

15. Jammer I, Wickboldt N, Sander M, et al. Standards for definitions and use of outcome measures for clinical effectiveness research in perioperative medicine: European Perioperative Clinical Outcome (EPCO) definitions: a statement from the ESA-ESICM Joint Taskforce on Perioperative Outcome Measures. Eur J Anaesthesiol 2015:32:88-105.

16. Austin PC. An introduction to propensity score methods for reducing the effects of confounding in observational studies. Multivariate Behav Res 2011:46:399-424.

17. Wu DH, Xu MY, Mao T, et al. Risk factors for intraoperative atrial fibrillation: a retrospective analysis of 10,563 lung operations in a single center. Ann Thorac Surg 2012;94:193-7.

18. Billmeier SE, Jaklitsch MT. Pulmonary surgery for malignant disease in the elderly. In: Rosenthal RA, Zenilman ME, Katlic MR, editors. Principles and Practice of Geriatric Surgery. 2nd ed. New York, NY: Springer, 2011:605-16.

19. Angele MK, Schwacha MG, Ayala A, et al. Effect of gender and sex hormones on immune responses following shock. Shock 2000;14:81-90.

20. Kimmerly DS, Wong S, Menon R, et al. Forebrain neural patterns associated with sex differences in autonomic and cardiovascular function during baroreceptor unloading. Am J Physiol Regul Integr Comp Physiol 2007:292:R715-22.

21. Nugent AC, Bain EE, Thayer JF, et al. Sex differences in the neural correlates of autonomic arousal: a pilot PET study. Int J Psychophysiol 2011;80:182-91.

22. Tada H, Sticherling C, Chough SP, et al. Gender and age differences in induced atrial fibrillation. Am J Cardiol 2001;88:436-8.

23. Shen J, Bailey M, Damiano RJ Jr. Surgery for lone atrial fibrillation: present state-of-the-art. Innovations (Phila) 2009;4:248-55.

24. Reichard P, Jensen-Urstad K, Ericsson M, et al. Autonomic neuropathy - a complication less pronounced in patients with type 1 diabetes mellitus who have lower blood glucose levels. Diabet Med 2000;17:860-6.

25. Kalus JS, White CM, Caron MF, et al. Indicators of atrial fibrillation risk in cardiac surgery patients on prophylactic amiodarone. Ann Thorac Surg 2004;77:1288-92.

26. Iwata T, Nagato K, Nakajima T, et al. Risk factors predictive of atrial fibrillation after lung cancer surgery. Surg Today 2016;46:877-86.

27. Muranishi Y, Sonobe M, Menju T, et al. Atrial fibrillation after lung cancer surgery: Incidence, severity, and risk factors. Surg Today 2017;47:252-8.

28. Li Y, Wang J, Yang F, et al. Indications for conversion of thoracoscopic to open thoracotomy in video-assisted thoracoscopic lobectomy. ANZ J Surg 2012;82:245-50. 
29. Li Y, Wang J. Analysis of lymph node impact on conversion of complete thoracoscopic lobectomy to open thoracotomy. Thorac Cancer 2015;6:704-8.

30. Roselli EE, Murthy SC, Rice TW, et al. Atrial fibrillation

Cite this article as: Tong C, Zhang Q, Liu Y, Xu M, $\mathrm{Wu}$ J, Cao H. Risk factors and outcomes of intraoperative atrial fibrillation in patients undergoing thoracoscopic anatomic lung surgery. Ann Transl Med 2021;9(7):543. doi: 10.21037/atm-205035 complicating lung cancer resection. J Thorac Cardiovasc Surg 2005;130:438-44.

(English Language Editor: B. Draper) 


\section{Supplementary}

Table $\mathbf{S 1}$ AF recovery during or after operation

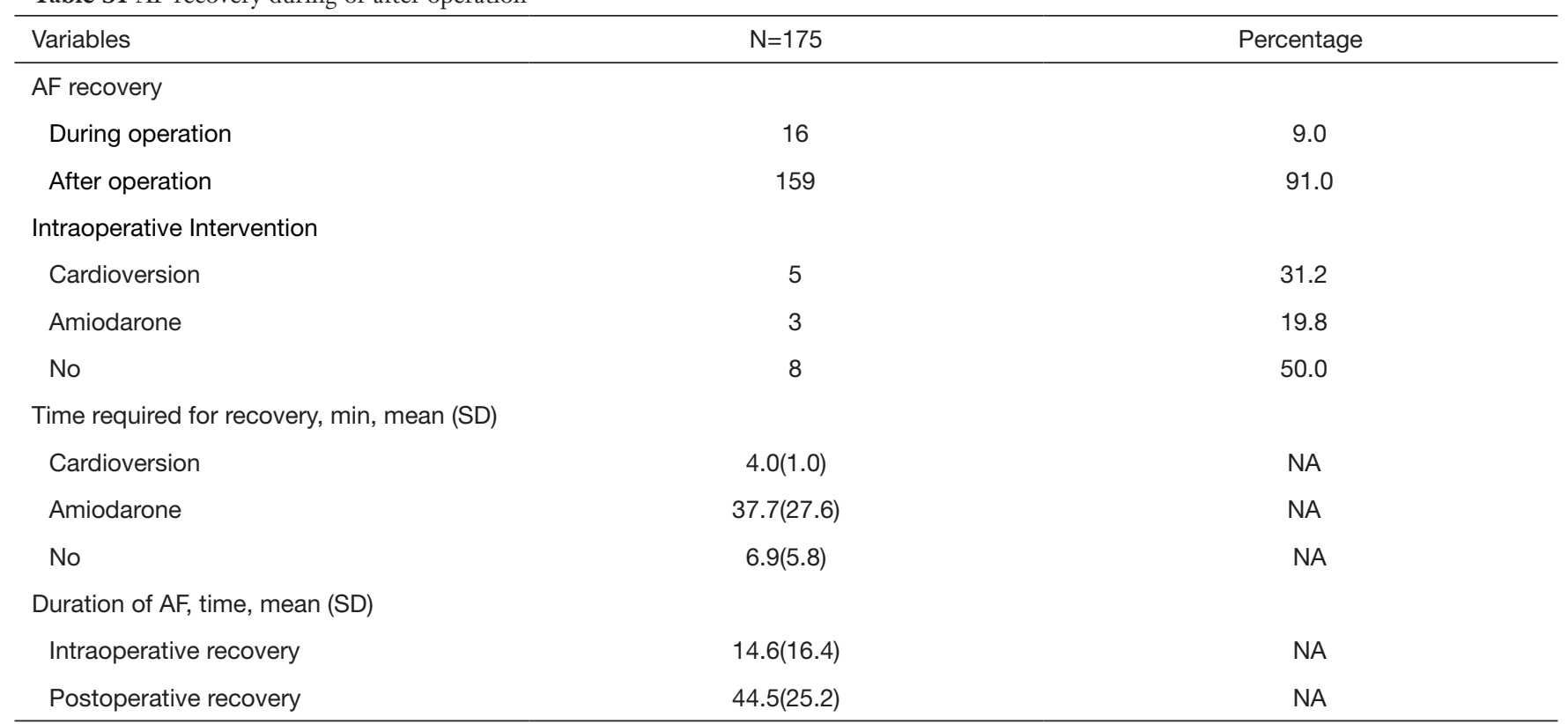

AF: Atrial fibrillation; NA: Not applicable

Table S2 Comparison of outcomes in AF recovery during or after operation

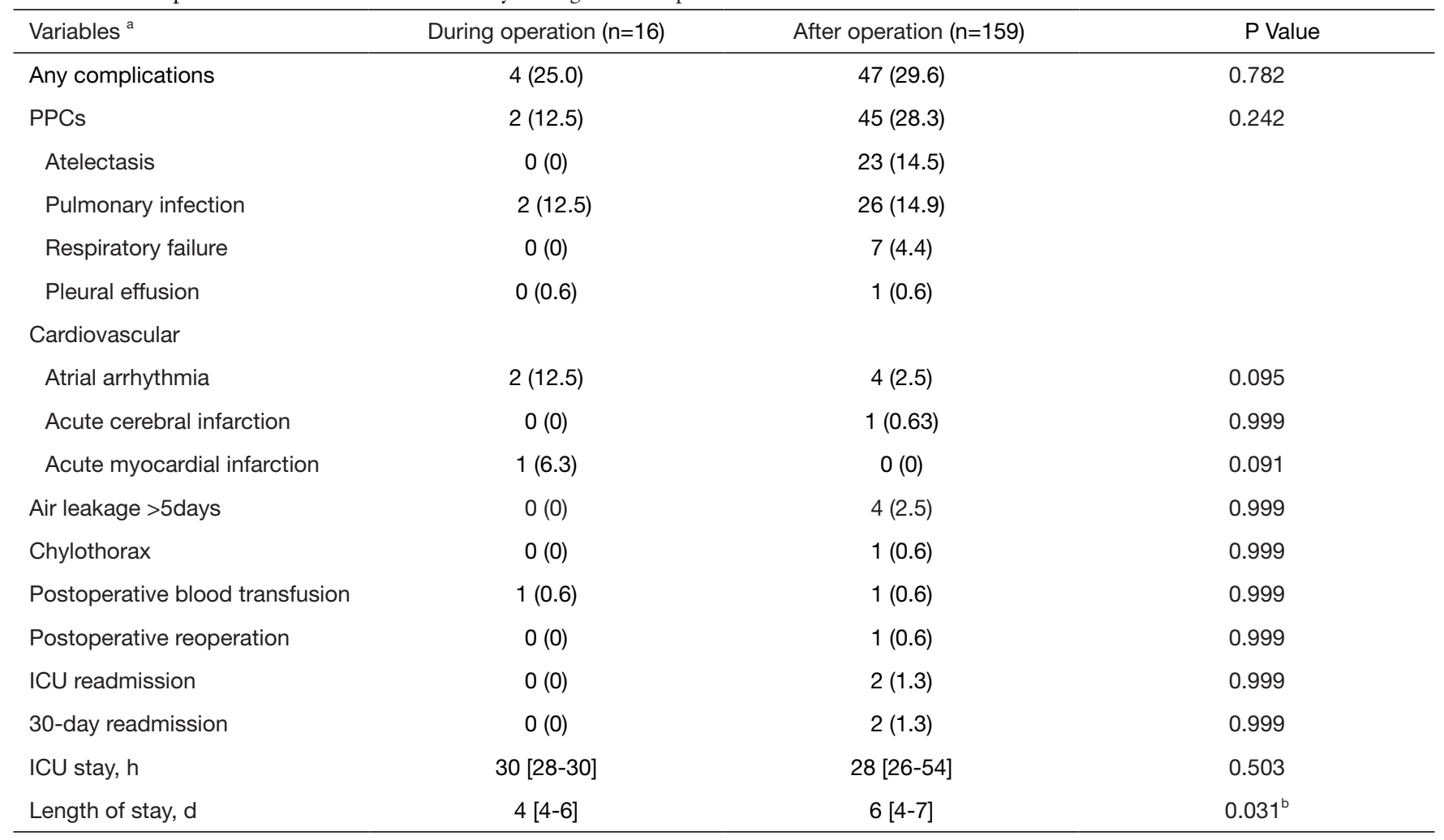

a Continuous data are shown as mean \pm standard deviation and categoric data as number $(\%)$; $b$ Statistically significant $(P<0.05)$. Length of stay and ICU stay, values as median (interquartile range). AF: Atrial fibrillation; PPCs: postoperative pulmonary complications; ICU: Intensive care unit. 